\title{
NOVEL GROUNDED CAPACITOR ALL-PASS AND NOTCH FILTERS USING CURRENT CONVEYORS AND DIFFERENTIAL AMPLIFIER
}

\author{
R. SARASWAT ${ }^{a}, K \cdot P A L^{b}, *$ and S. RANA ${ }^{c}$ \\ aScientific Laboratory Instruments, Post Box. 78, Roorkee - 247 667, India; \\ ${ }^{b}$ D epartment of Earthquake Engineering, I.I.T. Roorkee, Roorkee - 247 667, India; \\ 'DAV Centenary Public School, Hardwar - 249 404, India
}

(Received 16 August 2002; In final form 18 November 2002)

\begin{abstract}
Three circuits each realizing second-order all-pass/notch filter transfer functions are reported. All circuits use grounded capacitors and are suitable for IC implementation. These circuits offer the advantages of high input impedance and low output impedance and are superior to all earlier realisations.
\end{abstract}

Keywords: Active filters; All-pass filters; Notch filters; Current conveyor

\section{INTRODUCTION}

The second generation current conveyor (CCII) has received considerable attention in the literature as it can realise various filters, oscillators and inductances superior to operational amplifier versions [1-5]. It has been most successful in the realisation of a desired circuit with grounded capacitors which are preferred from the IC implementation point of view $[6,7]$. There exists a number of circuits using current conveyors realising first- and secondorder all-pass transfer function $[4,5,8,9]$, however circuits having high input impedance, low output impedance and using grounded capacitors are not available for realisation of second-order all-pass and notch filter functions, having some distinct advantages. In this paper three circuits have been reported which have the above-mentioned features.

\section{CIRCUIT DESCRIPTIONS}

The proposed circuits are shown in Figures 1-3. The voltage transfer function of the circuit of Figure 1 assuming $\mathrm{CCll}$ to be ideal is given by

$$
\frac{V_{0}}{V_{i}}=\frac{\left(1+s^{2} C_{1} C_{2} R_{1} R_{2}\right)+s\left(C_{1} R_{1}+C_{2} R_{2}-C_{1} R_{2}\right)}{\left(1+s^{2} C_{1} C_{2} R_{1} R_{2}\right)+s\left(C_{1} R_{1}+C_{2} R_{2}\right)} .
$$

\footnotetext{
* Corresponding author.
} 


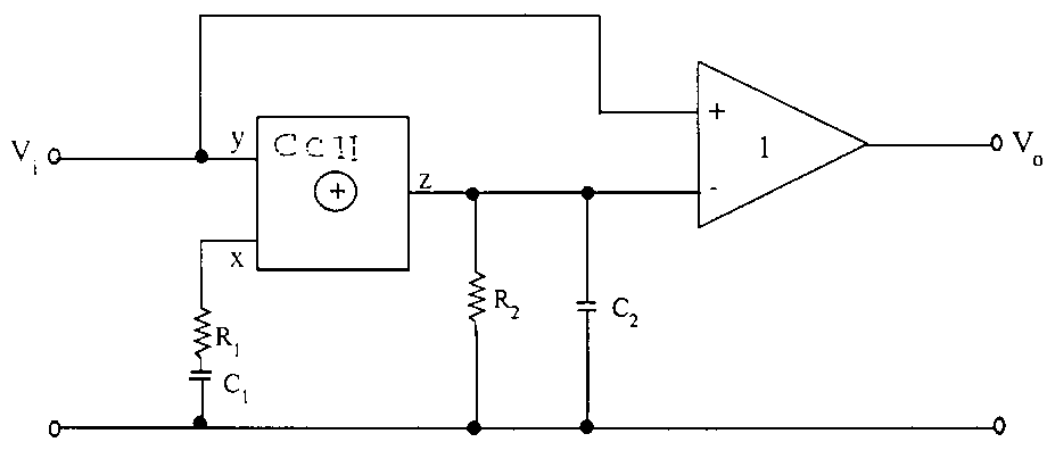

FIGURE 1 An active second-order all-pass/notch filter.

The circuit is given an all-pass function if

$$
\frac{C_{2}}{C_{1}}=\frac{1}{2}-\frac{R_{1}}{R_{2}}
$$

and to simplify the design, select

$$
C_{1}=4 C_{2}=4 C \text { and } R_{2}=4 R_{1}=4 R .
$$

Eq. (1) becomes

$$
\frac{V_{0}}{V_{i}}=\frac{1+16 s^{2} R^{2} C^{2}-8 s R C}{1+16 s^{2} R^{2} C^{2}+8 s R C}
$$

which represents an all-pass function. The circuit behaves as a notch filter, if

$$
\frac{C_{2}}{C_{1}}=1-\frac{R_{1}}{R_{2}}
$$

and to simplify the design, select

$$
\mathrm{C}_{1}=2 \mathrm{C}_{2}=2 \mathrm{C} \text { and } \mathrm{R}_{2}=2 \mathrm{R}_{1}=2 \mathrm{R} \text {. }
$$

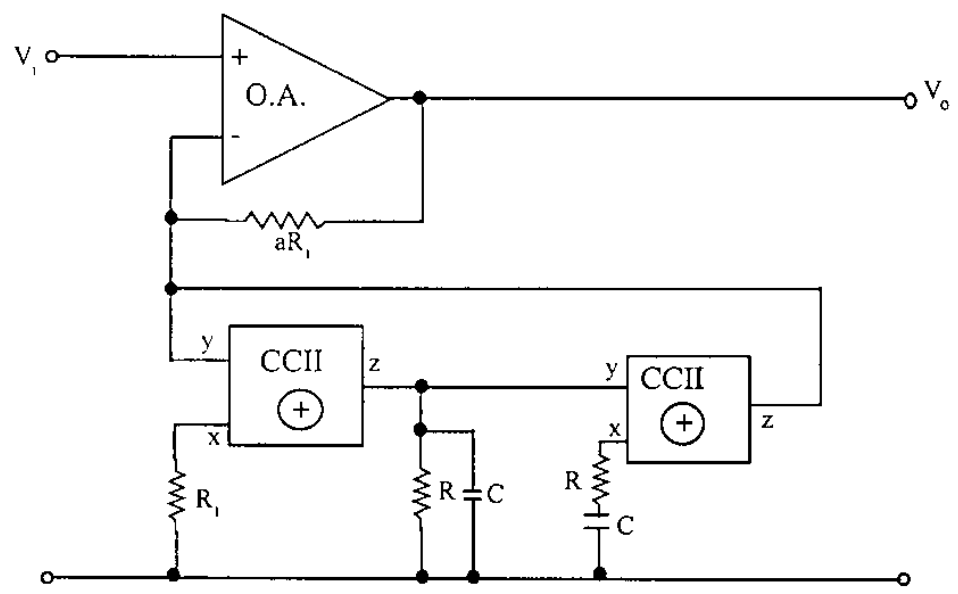

FIGURE 2 A novel second-order all-pass/notch filter realisation. 


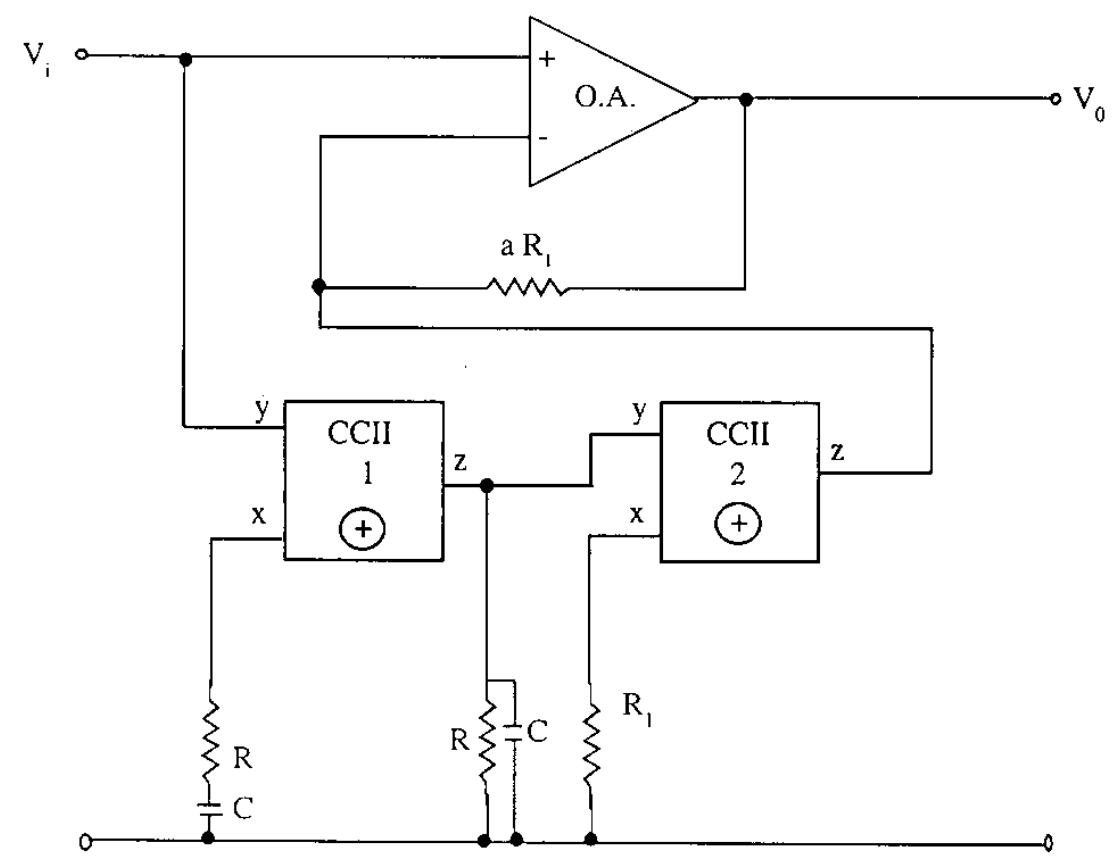

FIGURE 3 A nother novel second-order all-pass/notch filter realisation.

Eq. (1) becomes

$$
\frac{V_{0}}{V_{i}}=\frac{1+4 s^{2} R^{2} C^{2}}{1+4 s^{2} R^{2} C^{2}+4 s R C}
$$

Eq. (7) represents a notch transfer function. The circuit has high input impedance, low output impedance and uses grounded capacitors but suffers with the disadvantage of unequal $R_{1}, R_{2}$ and $C_{1}, C_{2}$ which makes it difficult to tune at a particular frequency. This disadvantage is rectified in the circuits of Figures 2 and 3 . B oth the circuits have the same voltage transfer function

$$
\frac{V_{0}}{V_{i}}=\frac{1+s^{2} R^{2} C^{2}+s C R(2-a)}{1+s^{2} R^{2} C^{2}+2 s C R}
$$

If $\mathrm{a}=4$ the circuit behaves as an all-pass function having voltage transfer function

$$
\frac{V_{0}}{V_{i}}=\frac{1+s^{2} R^{2} C^{2}-2 s C R}{1+s^{2} R^{2} C^{2}+2 s C R}
$$

For $\mathrm{a}=2$, Eq. (8) represents a notch filter given by

$$
\frac{V_{0}}{V_{i}}=\frac{1+s^{2} R^{2} C^{2}}{1+s^{2} R^{2} C^{2}+2 s C R}
$$


The circuits have the following advantages

(i) high input impedance

(ii) low output impedance

(iii) easy tuning through resistances Rs as both resistances are of equal values

(iv) suitability for IC implementation as they use grounded capacitors [6].

The circuits of Figures 2 and 3 are superior to all earlier realisations. As compared to the earlier novel realisation [8] it has low output impedance and easy tunability as the circuit [8] can not be designed for equal values of resistances or capacitances responsible for phase shift control or notch frequency tuning.

\section{EXPERIMENTAL RESULTS}

The circuits of Figures 2 and 3 were tested as notch filter and all-pass filter for the following component values

$$
\begin{aligned}
\mathrm{R} & =10 \mathrm{~K} \Omega, & \mathrm{C}=0.01 \mu \mathrm{F} \\
\mathrm{R}_{1} & =10 \mathrm{~K} \Omega, & \mathrm{a}=2,4 .
\end{aligned}
$$

The CCII $\oplus$ circuit reported by Huertas [10] was used and in its realisation, operational amplifiers IC-741 were used. The experimental results confirm the theory.

\section{CONCLUSIONS}

Three circuits realising all-pass/notch filters have been reported. The circuit offers advantages of high input impedance, low output impedance, grounded capacitor and two circuits have easier phase tuning facility than earlier circuits. It has been shown that a combination of operational amplifier and CCII results in better filter realisation than purely CCII-based realisations.

\section{References}

[1] Senani, R. (1979). N ew canonic single resistance controlled sinusoidal oscillator using single current conveyors. Electronics Letters, 15, 568-569.

[2] Senani, R. (1979). N ovel active RC circuit for floating inductor simulation. Electronics Letters, 15(21), 679-680.

[3] Pal, K. (1984). N ovel floating inductance using current conveyors. Electronics Letters, 17, 638.

[4] Pal, K. (1981). Realisation of current conveyor all-pass networks. International Journal of Electronics, $12,30-31$.

[5] Soliman, A. M . (1973). Inductorless realisation of all-pass transfer function using the current conveyors. IEEE Trans. Circuit Theory, CT-20, 80-81.

[6] Bhusan, M. and Newcomb, R. W. (1967). Grounding of capacitors in integrated circuits. Electronics Letters, 3, 148-149.

[7] Patranabis, D. and Paul, A. N. (1979). Novel capacitors floatation scheme. Electronics Letters, 3(15), 688-689.

[8] Pal, K . and Singh, R. (1982). Inductor less current conveyor all-pass filter using grounded capacitors. Electronics Letters, 18(1), 47.

[9] Pal, K. (1991). All-pass network using current conveyors. Microelectronics J ournal, 22(4), 53-56.

[10] Huertas, J. L. (1980). Circuit implementation of current conveyor. Electronics Letters, 16, 225-226. 

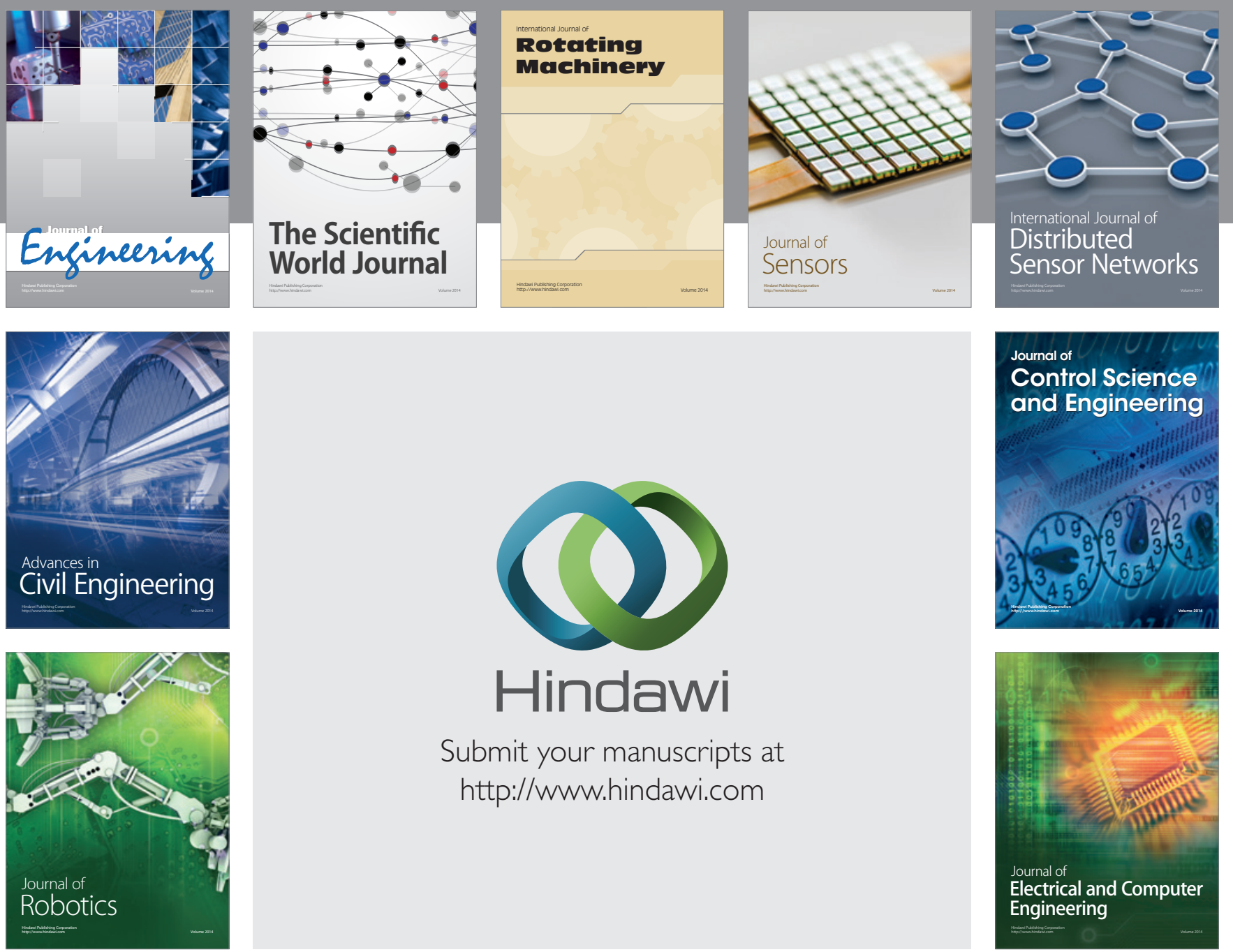

Submit your manuscripts at

http://www.hindawi.com
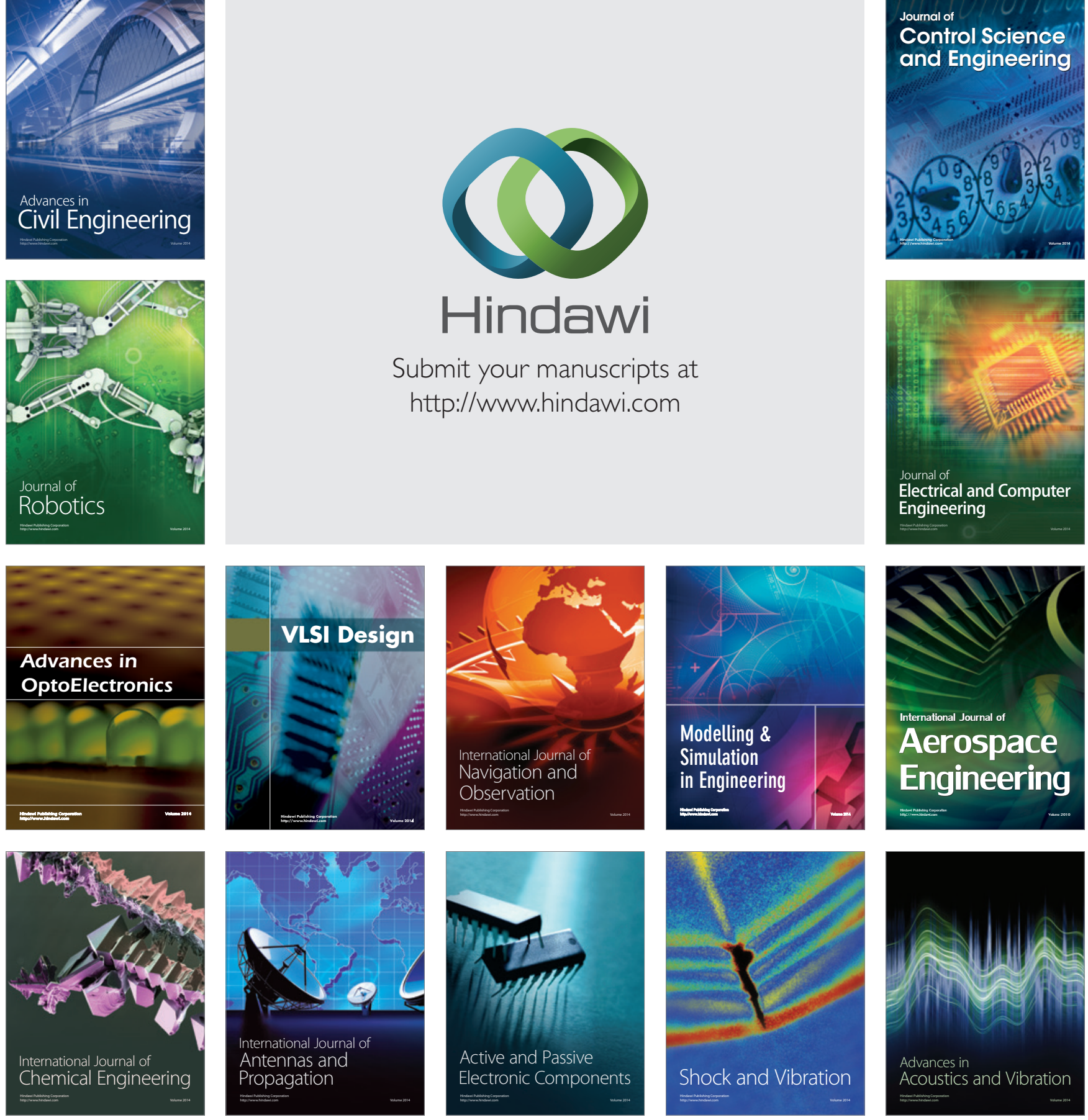